\title{
El artículo 18, inciso 3, del Código Procesal Penal: riesgos y posibilidades
}

\author{
WILFREDO ARDITO VEGA*
}

\begin{abstract}
SUMARIO: INTRODUCCIÓN.- I. EXCEPCIÓN AL PRINCIPIO DE LA UNIDAD Y EXCLUSIVIDADDELAFUNCIÓN JURISDICCIONAL.-II.INSTANCIA FACULTADA PARA ADMINISTRAR JUSTICIA.- III. COMPETENCIA FACULTATIVA.IV. COMPETENCIA TERRITORIAL.- $\quad$ V. COMPETENCIA PERSONAL.VI. COMPETENCIA MATERIAL.- VII. PROCEDIMIENTO.- VIII. EL LÍMITE DE LOS DERECHOS FUNDAMENTALES.- IX. LEY DE COORDINACIÓN.- X. LA POSIBILIDAD DE APELAR A UNA INSTANCIA ESTATAL.- XI. LOS LÍMITES DE LA JURISDICCIÓN COMUNAL Y RONDERA.- XII. EL PELIGROSO RELATIVISMO CULTURAL.- XIII. UNA ALTERNATIVA DE SOLUCIÓN.- XIV. CONCLUSIONES.
\end{abstract}

\section{INTRODUCCIÓN}

Con relación a las zonas rurales del Perú, el aporte más interesante del Código Procesal Penal (CPP) es el artículo 18, inciso 3, que señala que las autoridades del sistema penal no pueden intervenir cuando ya han ejercido su competencia las autoridades comunales, de acuerdo al artículo 149 de la Constitución: «ARTÍCULO 18. Límites de la jurisdicción penal ordinaria.- La jurisdicción penal ordinaria no es competente para conocer: [...] 3. De los hechos punibles en los casos previstos en el artículo 149 de la Constitución».

Hasta la promulgación del Código Procesal Penal, el artículo 149 había pasado desapercibido para muchos juristas.

Artículo 149: Las autoridades de las Comunidades Campesinas y Nativas, con el apoyo de las rondas campesinas, pueden ejercer funciones jurisdiccionales dentro de su ámbito territorial, de conformidad con el Derecho consuetudinario, siempre que no violen los derechos fundamentales de la persona. La ley establece las formas de coordinación de dicha jurisdicción especial con los Juzgados de Paz y con las demás instancias del Poder Judicial.

En el momento de su promulgación, este artículo no contaba con el respaldo del Ministerio Público o el Poder Judicial, y ambas entidades lo percibieron con recelo.

* Es abogado por la Pontificia Universidad Católica del Perú, magíster en Derecho Internacional de los Derechos Humanos por la Universidad de Essex y fundador de la Mesa contra el Racismo de la Coordinadora Nacional de Derechos Humanos. Conduce talleres de capacitación sobre la discriminación y promueve acciones de vigilancia ciudadana a nivel nacional. 
Chirinos Soto expresaba la opinión de muchos magistrados, al considerar este artículo como un texto «complicado e inquietante», que podría tener consecuencias muy negativas para la administración de justicia ${ }^{1}$ por su visión muy despectiva sobre las comunidades campesinas y nativas.

Más de quince años después, al producirse la paulatina aplicación del Código Procesal Penal a los distritos judiciales donde las rondas campesinas y las comunidades nativas y campesinas desarrollan sus prácticas de administración de justicia, se registran los primeros conflictos, debido a que, más bien, numerosos magistrados y fiscales se están rehusando a intervenir frente a delitos ocurridos en las comunidades, pese a las denuncias presentadas por la propia población.

A continuación, analizaremos con más detalle el artículo 149 de la Constitución para saber cuáles pueden ser las consecuencias concretas del nuevo Código Procesal Penal.

\section{EXCEPCIÓN AL PRINCIPIO DE LA UNIDAD Y EXCLUSIVIDAD DELAFUNCIÓN JURISDICCIONAL} El artículo 149 explícitamente señala que las autoridades comunales tienen funciones jurisdiccionales; es decir, no solamente ejercen la función de resolver conflictos o promover conciliaciones.

Una diferencia fundamental entre los mecanismos de resolución de conflictos y la administración de justicia es que en los primeros las partes voluntariamente aceptan y, eventualmente, llegan a un acuerdo. En cambio, las autoridades que ejercen la función jurisdiccional pueden compeler a las partes para que comparezcan, pueden tomar decisiones y pueden disponer su ejecución por medio de la coacción.

1 Afirmó al respecto: «[...] no se sabe ni se barrunta de qué manera administrarían justicia estas comunidades, ni cuáles serían los alcances de su jurisdicción. Queremos creer que únicamente estarían facultadas para resolver conflictos de carácter privado, sin ingresar al campo de la justicia penal, pues de lo contrario, se vulneraría el principio de legalidad, fundamento inconmovible del ejercicio del derecho de castigar, como atributo privativo del Estado» (p. 321). Señala, además, que la costumbre solo puede tener vigencia cuando la ley lo permite (p. 322). En un evidente desconocimiento de la realidad del mundo rural, llega a afirmar que este artículo puede generar alteraciones a la paz y concordia existentes en las comunidades campesinas (ibíd) y que daría pie para muchos abusos, generando la aparición de «satrapías». Concluye su crítica refiriéndose a la posible ley de coordinación: "La elaboración de esa ley va a demandar una actividad tan intrincada y compleja, que probablemente jamás se llegue a expedir. Ojalá que así sea» (ibíd). Entre las pocas opiniones favorables desde los ámbitos académicos no ligados directamente a las rondas, tenemos a Enrique Bernales, quien sostuvo que el artículo 149 se trataba de una norma audaz que rompe con la concepción tradicional, sumamente legalista, del Poder Judicial. Bernales resalta que el Derecho consuetudinario pasa a ser reconocido como Derecho en sí mismo y no como una simple fuente. Además, valora el artículo 149 como un mecanismo para garantizar el acceso a la justicia, al permitir que la población pudiera actuar desde su propia cultura (p. 592). Marcial Rubio es otro jurista que destaca el valor del artículo 149 al mostrar su clara vinculación con el artículo 2, inciso 19, de la Constitución, así como con el Convenio 169 de la OIT. Señala que permite a las autoridades comunales tomar decisiones según sus propias costumbres en situaciones no previstas por la ley, pero inclusive así fueran contrarias a la ley (p. 200). Coincidimos con Rubio en que, si no existiera esta posibilidad, no habría un real reconocimiento del pluralismo jurídico. El artículo 149 no plantea que las autoridades comunales apliquen la ley estatal, sino su propio derecho, y, precisamente al otorgar esta facultad, es que solamente coloca los derechos humanos como límite. 
De esta manera, junto con el Poder Judicial, el fuero militar y el fuero arbitral, las autoridades comunales son una instancia reconocida por la Constitución para la administración de justicia.

Como se puede apreciar, el artículo 149 no solamente reconoce la jurisdicción comunal, sino la normatividad propia de la población y la institucionalidad comunal, es decir a las autoridades que están a cargo de la administración de justicia².

Podemos decir, por lo tanto, que el artículo 149 consagra el reconocimiento del pluralismo jurídico en la administración de justicia en el Perú. Los constituyentes de 1993 no optaron por un pluralismo jurídico limitado, que implica simplemente admitir algunas prácticas culturales minoritarias, sino por un pluralismo jurídico amplio, que implica reconocer la existencia de otros sistemas jurídicos que funcionan dentro del mismo Estado 3 .

El pluralismo limitado está basado en la incorporación de algunos aspectos de los ordenamientos jurídicos distintos del estatal, mientras que el pluralismo amplio precisamente pasa al reconocimiento de otros sistemas jurídicos, con sus normas, valores, principios, autoridades y mecanismos de sanción ${ }^{4}$.

El reconocimiento de un pluralismo jurídico amplio, normalmente, se produce cuando ha ocurrido un cambio en las relaciones tradicionales de poder dentro de una sociedad ${ }^{5}$. De hecho, en otros países latinoamericanos, el pluralismo jurídico amplio ha sido reconocido cuando los indígenas habían alcanzado un fuerte protagonismo en la escena política.

De esta manera, en Colombia ${ }^{6}$, Bolivia $^{7}$ y Ecuador ${ }^{8}$ los artículos constitucionales que reconocen la función jurisdiccional de la población indígena fueron exigidos por esta misma población a través de sus repre-

2 BAZÁN CERDÁN, Jorge Fernando. La Jurisdicción Especial Indígena en el Derecho comparado latinoamericano. Cajamarca: Facultad de Derecho y Ciencia Política de la Universidad Privada Antonio Guillermo Urrelo, 2009, p. 17.

3 Griffiths emplea los conceptos weak y strong, respectivamente, pero creemos que los conceptos amplio y limitado grafican mejor el sentido de estas palabras.

4 HOEKEMA, André J. «European Legal Encounters: Cases of Interlegality». Journal of Legal Pluralism and Unofficial Law. Birmingham, $\mathrm{N}^{\circ}$ 51, 2005, p. 15.

5 Ibíd., p. 3.

6 «Artículo 246. Las autoridades de los pueblos indígenas podrán ejercer funciones jurisdiccionales dentro de su ámbito territorial, de conformidad con sus propias normas y procedimientos, siempre que no sean contrarios a la Constitución y las leyes de la República. La ley establecerá las formas de coordinación de esta jurisdicción especial con el sistema judicial nacional» (Constitución de 1992).

7 «Artículo 190. I. Las naciones y pueblos indígena originario campesinos ejercerán sus funciones jurisdiccionales y de competencia a través de sus autoridades, y aplicarán sus principios, valores culturales, normas y procedimientos propios" (Constitución de 2008).

8 «Artículo 171. Las autoridades de las comunidades, pueblos y nacionalidades indígenas ejercerán funciones jurisdiccionales, con base en sus tradiciones ancestrales y su derecho propio, dentro de su ámbito territorial, con garantía de participación y decisión de las mujeres. Las autoridades aplicarán normas y procedimientos propios para la solución de sus conflictos internos, y que no sean contrarios a la Constitución y a los derechos humanos reconocidos en instrumentos internacionales. El Estado garantizará que las decisiones de la jurisdicción indígena sean respetadas por las instituciones y autoridades públicas. Dichas decisiones estarán sujetas al control de constitucionalidad. La ley establecerá los mecanismos de coordinación y cooperación entre la jurisdicción indígena y la jurisdicción ordinaria» (Constitución de 2009).

EL ARTÍCULO 18, INCISO 3 , DEL CÓDIGO PROCESAL PENAL: RIESGOS Y POSIBILIDADES 
sentantes en asambleas o congresos constituyentes. En el caso del Perú, no existía una representación indígena en el Congreso Constituyente elegido en 1992 y el artículo 149 fue más bien una iniciativa de las ONG y de las instituciones que trabajaban con las organizaciones campesinas, que de la propia población.

\section{II.INSTANCIA FACULTADA PARA ADMINISTRAR JUSTICIA}

\section{II.1. Pueblos indígenas o comunidades}

El artículo 149 no reconoce funciones jurisdiccionales a pueblos indígenas, naciones o nacionalidades, como ocurre en las constituciones de los países vecinos, sino solamente a las comunidades. A nosotros nos parece adecuado que el reconocimiento haya sido realizado de esta manera, porque en el Perú los pueblos indígenas no están organizados en cuanto a tales con autoridades que ejerzan la función de administrar justicia, mientras que las comunidades campesinas y nativas sí tienen una gran vigencia. La mención a pueblos indígenas — una entidad que, al menos en las zonas andinas, carece de referente concreto- volvería inaplicable dicho reconocimiento.

\section{II.2. Autoridades comunales}

De otro lado, dentro de la comunidad, la Constitución reconoce la función jurisdiccional a las autoridades comunales, que deben atender las demandas de justicia de todos los habitantes. De acuerdo a la legislación vigente, las autoridades comunales son el presidente de la comunidad, la junta directiva y la asamblea general. Se trata de una estructura que deriva de las normas sobre asociaciones civiles, que con el tiempo ha sido asumida por la población rural. También podrían estar incluidas autoridades tradicionales, como alcaldes de varas, si ejercen este cargo.

No se reconoce, sin embargo, esta facultad a las autoridades familiares, que no ejercen esta función para todos los miembros de su comunidad ni actúan de manera permanente. Es el caso de los padres o padrinos, quienes en zonas andinas con frecuencia resuelven conflictos familiares de las personas que están consideradas a su cargo.

De igual manera, el artículo 149 no reconoce la práctica cultural de aquellos indígenas amazónicos que, cuando un familiar suyo ha fallecido súbitamente, sienten la obligación de obtener justicia mediante la muerte del supuesto agresor sobrenatural. Este es un caso de autocomposición, no del ejercicio de una función jurisdiccional por una autoridad.

El artículo 149 no reconoce esta función a las autoridades políticas, como los tenientes gobernadores, que muchas veces resuelven conflictos a petición de los involucrados. Ahora bien, podría interpretarse que 
los tenientes gobernadores son autoridades comunales, como también lo es el agente municipal o el juez de paz. En realidad, esta es la interpretación de muchas comunidades porque acuden a dichas autoridades para buscar justicia, y no al presidente o a la asamblea.

\section{II.3. Las rondas campesinas}

\section{II.3.1. La interpretación literal}

El aspecto de este artículo que ha generado más polémica se refiere al rol de las rondas campesinas: literalmente, estas no aparecían como una instancia a cargo de administrar justicia, sino que eran solamente un organismo de «apoyo» a las autoridades comunales. Es decir, mediante las rondas era posible ejecutar una medida coactiva, garantizar el cumplimiento de las decisiones o conducir a una persona renuente a acudir al llamado de las autoridades. Podemos decir que este artículo reducía las rondas a una función similar a la de la Policía Nacional.

El problema es que la mayoría de rondas campesinas sí ejercen la función de administración de justicia, especialmente en aquellos lugares del Perú donde no existen comunidades campesinas, como Cajamarca o San Martín.

Sin embargo, los integrantes del Congreso Constituyente Democrático identificaban a las rondas campesinas con temas de seguridad y no de administración de justicia. A nuestro entender, las confundieron con los comités de autodefensa formados para la lucha antisubversiva; tomando en cuenta su carácter estrictamente militar, consideraron que sería peligroso otorgarles la función de administrar justicia.

Además, los comités de autodefensa estaban diseñados como una organización temporal que debía existir solamente mientras durase el fenómeno subversivo, y hacia fines del año 1993 era visible que este problema estaba declinando. Finalmente, muchos integrantes de comités de autodefensa habían sido vinculados a violaciones de los derechos humanos, por lo que era sumamente delicado brindarles la posibilidad de administrar justicia.

Esta confusión, que todavía subsiste en sectores urbanos, llevó a que la administración de justicia por parte de las rondas campesinas no tuviera un adecuado reconocimiento constitucional.

\section{II.3.2. Primeras decisiones del Poder Judicial}

La ausencia de reconocimiento constitucional de la función jurisdiccional ha generado que se entablen numerosos procesos contra los ronderos por coacción, secuestro, usurpación de funciones y otros delitos.

Uno de los casos que causó más conmoción a la opinión pública se produjo en 2004, cuando diez ronderos, siete hombres y tres mujeres del

EL ARTÍCULO 18,

INCISO 3 ,

DEL CÓDIGO

PROCESAL PENAL:

RIESGOS Y

POSIBILIDADES 
poblado de Pueblo Libre, en las cercanías de Moyobamba, fueron condenados por la Corte Superior de San Martín a prisión por el delito de secuestro, aunque en realidad se trataba de la aplicación de la cadena ronderil a un grupo de violadores y asaltantes ${ }^{9}$. La Corte Superior no llegó a individualizar mayor responsabilidad en los sentenciados, salvo el hecho de que formaban la junta directiva de la ronda. Dos de ellos no se encontraban en Pueblo Libre cuando se produjeron los hechos ${ }^{10}$.

En la sentencia 975-04 del 9 de junio de 2004, la Sala Penal Transitoria de la Corte Suprema absolvió a los ronderos al señalar que el artículo 149 efectivamente permite a las rondas campesinas administrar justicia. La sentencia precisó que, además, las rondas están facultadas para detener personas, procesarlas y aplicar las sanciones necesarias, siempre que no vulneren los derechos fundamentales. Pese a su trascendencia, la sentencia 975-04 solamente tenía vigencia para el caso concreto, sin alcanzar carácter vinculante para otros procesos.

En mayo de 2008 se realizó el Pleno Jurisdiccional Regional Penal de la región Amazónica, durante el cual los magistrados de las cortes superiores de Amazonas y San Martín promovieron que se reflejara la necesidad de reconocer la función jurisdiccional de las rondas campesinas ${ }^{11}$. Los acuerdos de esta reunión tampoco tenían carácter vinculante, pero permitieron apreciar un cambio en la percepción de la Corte Superior de San Martín, años antes reacia a admitir la competencia de las rondas.

\section{II.3.3. El Acuerdo Plenario de la Corte Suprema}

Finalmente, la Sala Penal Permanente de la Corte Suprema y las salas penales transitorias decidieron convocar a un pleno jurisdiccional respecto de la posibilidad de reconocer la administración de justicia por parte de las rondas campesinas. Se llegó a una decisión definitiva mediante el Acuerdo Plenario del 13 de noviembre de 2009. Este acuerdo sí posee el carácter de precedente vinculante, en concordancia con la función de unificación jurisprudencial de la Corte Suprema ${ }^{12}$.

El Acuerdo Plenario analiza de manera detallada el texto constitucional, para lo cual toma en cuenta la problemática de la justicia en las zonas rurales. Precisa que, cuando la Constitución reconoce en su artículo 2, inciso 19 como derecho individual la identidad étnica y cultural de las personas, y protege la pluralidad étnica y cultural de la nación, está estableciendo un principio fundamental que debe regir al Estado peruano ${ }^{13}$.

9 La cadena ronderil es una sanción tradicional que consiste en que el sentenciado debe patrullar con los ronderos y luego es llevado de caserío en caserío para seguir patrullando durante diversos turnos de ronda.

10 En relación con este caso, puede leerse el libro de Serafín Osorio y Wuille Ruiz: El legado de las rondas campesinas de Pueblo Libre, Moyobamba, San Martín. Una aproximación sociológica y jurídica. Lima: Projur, SER, y Paz y Esperanza, 2009.

11 Pleno Jurisdiccional, 11.

12 Acuerdo Plenario, 4.

13 Acuerdo Plenario, 6. 
De esta forma, explícitamente se reconoce la existencia de pluralismo jurídico en el Perú, y se precisa que esta situación implica que varios sistemas coexisten y que es normal que en la práctica «colisionan, se contraponen y hasta compiten $»^{14}$.

En relación con las rondas campesinas, el Acuerdo Plenario considera que es necesario salir de una interpretación literal y restrictiva respecto del artículo $149^{15}$,y recuerda que las rondas surgieron precisamente en contextos donde no había comunidades campesinas. Las rondas fueron entonces la forma en que los campesinos lograron «expresar su organización comunal» y se convirtieron en «espacios de afirmación de su identidad colectiva».

Los magistrados señalan que «el fundamento del artículo 149 de la Constitución es que los pueblos con una tradición e identidad propias en sede rural resuelvan sus conflictos con arreglo a sus propias normas e instituciones», por lo que no reconocer esta facultad a las rondas campesinas implicaría un trato discriminatorio hacia esta población ${ }^{16}$.

El Acuerdo Plenario señala que las rondas campesinas son una forma de autoridad comunal en aquellos lugares donde no existen comunidades campesinas o nativas reconocidas en cuanto tales. Resulta importante señalar que lo comunal no aparece determinado solamente por el reconocimiento legal que proporciona una norma, sino por la existencia en la realidad de un sistema y una organización comunal. Además, se reconoce que mantienen los ideales andinos de solidaridad, trabajo comunal e idea de progreso ${ }^{17}$.

\section{COMPETENCIA FACULTATIVA}

La lectura del artículo 149 nos muestra que la Constitución no establece una jurisdicción obligatoria para las autoridades de las comunidades campesinas o nativas, y que estas pueden asumir la jurisdicción o dejarla en manos de agentes estatales.

De esta forma, en la zona andina es frecuente que las autoridades comunales prefieran dedicarse a asuntos económicos o productivos y deleguen la función jurisdiccional al juez de paz, que en realidad en tales lugares también es una autoridad comunal. En las comunidades campesinas que subsisten en la costa, prácticamente no se ejerce esta función.

14 Peña, citado por Acuerdo Plenario, 6.

15 Juan Carlos Ruiz Molleda desarrolla con claridad la crítica a esta interpretación literal: implicaría una contradicción con el resto del texto constitucional y llevaría a que, en la práctica, los derechos humanos no tengan vigencia en las zonas donde operan las rondas campesinas (mayo 2008, pp. 44-46).

EL ARTÍCULO 18,

INCISO 3 ,

DEL CÓDIGO

PROCESAL PENAL:

RIESGOS Y

POSIBILIDADES 
En otros países como Bolivia o Colombia, donde no existe la justicia de paz en zonas rurales ${ }^{18}$, se ha planteado con carácter obligatorio acudir a la jurisdicción indígena; pero creemos que en el caso del Perú no sería muy lógico que se impusiera esta función como obligatoria para las autoridades comunales, sobre todo en los casos en que se sienten poco preparadas para ello, debido a la gravedad de los problemas o porque consideran preferible que la instancia estatal los resuelva.

El carácter facultativo de la jurisdicción comunal también permite que la población pueda sentirse libre para que determinados problemas sean vistos por una autoridad estatal. No se plantea, por lo tanto, que todos los delitos que se producen dentro de una comunidad campesina o nativa se encuentren fuera de la competencia del Derecho estatal.

\section{COMPETENCIA TERRITORIAL}

El artículo 149 establece con claridad un límite territorial para el ejercicio de la administración de justicia por parte de las autoridades comunales. No podría, por lo tanto, plantearse que las autoridades comunales administren justicia frente a un hecho que se produce fuera de su territorio, aunque sea entre sus integrantes.

Esta característica le da un sentido más complejo al territorio de una comunidad, que no solamente debe ser analizado desde el punto de vista del derecho de propiedad reconocido por el Código Civil. El territorio comunal constituye también el especio donde las autoridades comunales pueden ejercer jurisdicción.

Por eso, el artículo 149 se encuentra claramente en estrecha vinculación con el artículo 89, que reconoce los derechos territoriales de las comunidades campesinas y nativas, puesto que la seguridad respecto a un territorio es uno de los factores esenciales para que un grupo humano se pueda reproducir y ejerza su identidad ${ }^{19}$. El artículo 89 también reconoce la autonomía de las comunidades, lo cual implica permitir también su autorregulación.

Paradójicamente, el mismo artículo 89 ha debilitado la protección a las tierras comunales al facilitar su venta o su embargo, que estaban prohibidos o restringidos por las Constituciones anteriores, por lo cual, indirectamente, está afectando las posibilidades de las autoridades comunales de administrar justicia. 
Por otro lado, aunque la competencia esté restringida al territorio comunal, se entiende que sus decisiones tienen eficacia a nivel nacional porque las autoridades estatales y el resto de la sociedad deben respetarlas.

Sin embargo, de ninguna manera la competencia territorial debe interpretarse asumiendo que el Derecho estatal no tiene vigencia dentro del territorio de las comunidades campesinas o nativas.

En el caso de las rondas campesinas que no pertenecen a una comunidad, cuyos integrantes son pequeños propietarios, entendemos que el límite territorial serían las tierras de cada uno de los ronderos y las áreas comunes de los caseríos. Consideramos, no obstante, que sería oportuna una mejor determinación geográfica para precisar cuál es el territorio que corresponde a cada ronda.

\section{COMPETENCIA PERSONAL}

En cuanto a la competencia personal, la lectura del artículo 149 nos permite señalar que no se restringe a los habitantes de la comunidad ni a los integrantes del mismo grupo étnico. La jurisdicción comunal puede ser aplicada a todas las personas que se encuentran dentro del territorio de la comunidad.

Se trata de una importante precisión, puesto que con frecuencia las personas foráneas pueden cometer algún abuso dentro de la comunidad y frente a las instancias estatales tienen mayores posibilidades de ser favorecidas, debido a las barreras lingüísticas, geográficas o económicas que enfrentan los pobladores para acceder a la justicia. Esto, por ejemplo, ha venido sucediendo con los abigeos.

Una frecuente crítica es que las personas foráneas no tienen conocimiento de los patrones culturales de la comunidad, por lo que no deberían ser sancionados ${ }^{20}$. El Acuerdo Plenario precisa que las rondas son competentes para procesar foráneos con algunas condiciones, que creemos se aplican también a las comunidades. De esta manera, se señala que la conducta sancionada debe afectar el interés comunal o de una persona que se encuentre dentro del ámbito territorial de la ronda, así como el imputado deberá conocer el daño que está realizando a los valores comunitarios ${ }^{21}$.

En la mayoría de casos (abigeato, riñas, deudas, alimentos) se cumplen estas condiciones. Sin embargo, podría haber problemas con otras situaciones no sancionadas en el ordenamiento estatal — como

20 Se plantearía, por lo tanto, que en la comunidad se aplique a los foráneos una especie de «error culturalmente condicionado".

21 La persona foránea puede estar en tres supuestos para que la ronda pueda intervenir: «a. El agente debe haber advertido la lesión o puesta en peligro del interés comunal o de sus miembros. b El agente debe haber actuado con móviles egoístas pasa afectar a la institución comunal o c. El agente debe haber ofendido a sabiendas los valores y bienes jurídicos tradicionales de las rondas o sus integrantes» (Acuerdo Plenario, $10 \mathrm{C}$, ii.).

EL ARTÍCULO 18,

INCISO 3,

DEL CÓDIGO

PROCESAL PENAL:

RIESGOS Y

POSIBILIDADES 
el adulterio-, aunque normalmente quien vive en una comunidad sabe que esta conducta atenta contra los valores de la población.

Las precisiones realizadas por el Acuerdo Plenario pueden ser útiles para evitar que una persona sea sancionada por un hecho que desconocía, como ocurre en las acusaciones de carácter sobrenatural (brujería), más frecuentes en las comunidades nativas.

\section{COMPETENCIA MATERIAL}

Respecto a la competencia material, el artículo 149 no establece mayores límites, por lo que eventualmente una comunidad campesina o nativa podría administrar justicia sobre asuntos que el Derecho estatal considera civiles, incluyendo temas de familia, o asuntos de materia penal.

Consideramos que tampoco existe impedimento para que las autoridades comunales intervengan en conflictos que deriven de su propia cultura, como la situación de los convivientes o los entenados (hijastros). Creemos que también es factible una intervención en aquellos problemas que no existen para una persona occidental, como las situaciones de carácter sobrenatural, siempre que se produzcan entre los propios integrantes de la comunidad.

Pese a lo señalado, tenemos serias dudas con respecto a si una comunidad campesina o nativa debería estar facultada para procesar y sancionar delitos como homicidio, terrorismo o narcotráfico. $\mathrm{Al}$ respecto, resulta interesante estudiar la legislación comparada.

En Venezuela, la Ley Orgánica sobre Pueblos y Comunidades Indígenas reserva para la jurisdicción estatal el juzgamiento de delitos contra la seguridad y la integridad de la nación, corrupción, delitos contra el patrimonio público, delitos aduaneros, narcotráfico, tráfico de armas, crímenes organizados y crímenes internacionales: genocidio, delitos de lesa humanidad, crímenes de guerra y crímenes de agresión ${ }^{22}$.

Este criterio coincide con el que plantea el Código Procesal Penal de Paraguay, cuando señala que la competencia de las comunidades indígenas versa sobre hechos punibles que afecten bienes jurídicos propios de una comunidad o bienes personales de alguno de sus miembros, y no aquellos casos señalados en la norma venezolana, donde el agraviado es el Estado.

El Código Procesal Penal del Estado de Oaxaca, en México, mantiene la misma redacción que el código del Paraguay, pero además excluye de la competencia de las comunidades indígenas los casos de homicidio doloso, violación, violencia familiar, los delitos cometidos contra menores de 
doce años, los delitos agravados por el resultado de muerte y los delitos de asociación delictuosa ${ }^{23}$.

En el caso del artículo 149 creemos que sería más adecuado precisar la competencia material según el criterio de los ordenamientos de Venezuela y Paraguay: excluir de la competencia de las comunidades y rondas aquellos delitos que atentan contra el ordenamiento y los intereses estatales, así como los crímenes de lesa humanidad.

Concordamos también con el código de Oaxaca en que los casos de homicidio doloso deberían ser reservados para la jurisdicción estatal, debido a que este delito, por su gravedad, afecta seriamente el tejido social y resulta casi imposible restablecer la armonía y la reinserción del criminal. Sin embargo, el resto del listado puede ser sumamente restrictivo y podría llevar a situaciones de impunidad. Por ejemplo, si solamente la jurisdicción estatal atendiera casos de violencia familiar, en la práctica muchas mujeres no podrían acceder a los tribunales estatales.

\section{VII.PROCEDIMIENTO}

Según el artículo 149, las autoridades comunales deberán resolver las controversias que se susciten en su ámbito territorial mediante el Derecho consuetudinario. Ahora bien, creemos que el Derecho consuetudinario no debe ser considerado como las tradiciones más antiguas de una población, sino como normas, procedimientos y sanciones que en la actualidad cada comunidad asume como propios.

Realizamos esta precisión en primer lugar porque la actual estructura de comunidades campesinas y nativas es relativamente reciente: la mayor parte de las comunidades campesinas fueron organizadas tras la Reforma Agraria de 1969, con las precisiones legales del Estatuto de Comunidades Campesinas de 1970 y la ley 24656 de 1987. Las comunidades nativas tienen su actual organización desde 1974, y las rondas campesinas aparecen en 1976.

En segundo lugar, el Derecho consuetudinario evoluciona y aquellos criterios con los cuales un conflicto era resuelto antes pueden haber cambiado radicalmente. Por ejemplo, en muchos casos los padres estaban a cargo de elegir las parejas de sus hijos, las mujeres estaban totalmente subordinadas a sus maridos y los castigos físicos eran considerados la única forma de sanción. Paulatinamente, las comunidades y las rondas

23 «Artículo 414. Comunidades indígenas: Cuando se trate de delitos que afecten bienes jurídicos propios de un pueblo o comunidad indígena o bienes personales de alguno de sus miembros, y tanto el imputado como la víctima o, en su caso, sus familiares, acepten el modo como la comunidad ha resuelto el conflicto conforme a sus propios sistemas normativos en la regulación y solución de sus conflictos internos, se declarará la extinción de la acción penal. En estos casos, cualquier miembro de la comunidad indígena podrá solicitar que así se declare ante el juez competente. Se excluyen los casos de homicidio doloso, violación, violencia intrafamiliar, los delitos cometidos contra menores de doce años, los delitos agravados por el resultado de muerte y los delitos de asociación delictuosa».

EL ARTÍCULO 18,

INCISO 3,

DEL CÓDIGO

PROCESAL PENAL:

RIESGOS Y

POSIBILIDADES 
vienen incorporando mayores elementos de derechos humanos a sus procedimientos de administración de justicia.

En la actualidad, la expresión «Derecho consuetudinario» ha sido reemplazada en las constituciones latinoamericanas más recientes por la expresión «Derecho propio», que no acarrea mayores connotaciones de antigüedad $^{24}$.

El Acuerdo Plenario concuerda con las mencionadas constituciones, cuando define al Derecho consuetudinario como «un sistema normativo propio, entendido como conjunto de normas y potestad de regulación propia, como de la organización autónoma de sus instituciones para la decisión de los asuntos que reclaman la intervención de la jurisdicción comunal».

De esta forma, no está conformado necesariamente por prácticas ancestrales, sino como las respuestas actuales de una determinada colectividad para satisfacer sus demandas de justicia. El Acuerdo Plenario reconoce, así, el dinamismo existente dentro de la población rural y la posibilidad de cambiar e innovar.

\section{EL LÍMITEDELOS DERECHOS FUNDAMENTALES}

La Constitución de 1993 no establece restricciones a las autoridades comunales en cuanto a la competencia personal, la materia o la cuantía, sino en cuanto a la sanción, y exige el respeto por los derechos fundamentales. De esta manera, no se trata de un derecho absoluto de administración de justicia.

El Acuerdo Plenario realiza varias precisiones importantes con respecto a derechos como la integridad física y moral, al señalar que se encuentra prohibido que las rondas campesinas practiquen detenciones arbitrarias, golpeen, amenacen o humillen a una persona para que declare en un determinado sentido. Se menciona también la obligación de respetar el derecho de defensa ${ }^{25}$.

Nosotros creemos que las autoridades comunales y ronderas también están obligadas a respetar el derecho a la igualdad y el derecho a la justicia: frecuentemente, en las zonas rurales las mujeres se encuentran en una situación de subordinación y algunas autoridades comunales suelen ser muy permisivas frente a la violencia contra la mujer ${ }^{26}$.

24 El cambio ha sido visible en la reforma constitucional de México de 2001, en la Constitución de Bolivia de 2008 y en la Ecuador de 2009.

25 Acuerdo Plenario, 12.

26 En muchos grupos indígenas y, en general, en las culturas no occidentales, la situación de los derechos de la mujer representa una problemática donde existe frecuente conflicto entre los derechos culturales y los derechos individuales. 


\section{LEY DE COORDINACIÓN}

El artículo 149 no plantea que la jurisdicción comunal se desarrolle sin contacto alguno con la jurisdicción estatal, lo cual carecería de sentido dada la relación que las comunidades campesinas y nativas y las rondas establecen con el Estado.

Una ley de coordinación deberá regular las relaciones entre las dos jurisdicciones y plantearse si existirá una competencia específica para la jurisdicción comunal o la forma en que las decisiones que se toman en una jurisdicción sean reconocidas o ejecutadas por la otra.

Sin embargo, la ausencia de una ley de coordinación no implica que el artículo 149 no esté vigente todavía. Nosotros consideramos que la Constitución reconoció la facultad de administrar justicia a las autoridades comunales desde el mismo momento en que fue promulgada. La necesidad de una ley de coordinación tiene un carácter más bien operativo, que no restringe el ejercicio de dicha facultad ${ }^{27}$.

A lo largo de los últimos diecisiete años, la promulgación de esta norma ha quedado lamentablemente entrampada. Ello se ha debido en parte al desinterés del Poder Judicial, que no se manifestó interesado en establecer patrones de coordinación con la jurisdicción comunal.

Otra razón por la que la norma no ha sido promulgada es la realidad heterogénea de las prácticas de administración de justicia comunal. En algunos proyectos de ley se ha enfatizado una perspectiva indígena, que tiene muy poca relación con las rondas campesinas. En otros se ha planteado una exclusión de la jurisdicción estatal de las zonas rurales, lo cual no tiene mayor relación con las demandas de la propia población. Mediante esta norma pueden precisarse con claridad aquellas materias sobre cuyo conocimiento el Estado se reserva.

\section{LA POSIBILIDAD DE APELAR A UNA INSTANCIA ESTATAL}

Cabe preguntarse, sin embargo, si la solución que la jurisdicción comunal y rondera es definitiva o si las personas involucradas tienen la posibilidad de acudir a la administración de justicia estatal en caso de que no estuvieran de acuerdo con la decisión tomada. En el artículo 149 esta posibilidad no aparece pero tampoco se excluye, por lo que es interesante revisar la legislación comparada.

En Paraguay y el Estado de Oaxaca la acción penal solamente se extingue si la víctima o sus familiares están de acuerdo con el modo en que la comunidad ha resuelto el conflicto conforme a su propio Derecho

EL ARTÍCULO 18,

INCISO 3,

DEL CÓDIGO

PROCESAL PENAL:

RIESGOS Y

POSIBILIDADES 
consuetudinario $^{28}$. En caso de que no estén de acuerdo, pueden acudir a la jurisdicción estatal.

En Colombia existe la posibilidad, tanto para los agraviados como para los imputados, de acudir a la Corte Constitucional, que en los últimos años ha ido señalando los límites para el accionar de la jurisdicción indígena y ha dispuesto que algunas penas puedan ser corregidas. En Venezuela, en cambio, se señala que la forma en que las comunidades resuelven es definitiva, lo cual no da lugar a acudir a tribunales estatales ${ }^{29}$.

\section{LOS LIIMITES DE LA JURISDICCIÓN COMUNAL Y RONDERA}

Para funcionar adecuadamente, la jurisdicción comunal y rondera requiere que realmente exista un ámbito comunitario, es decir niveles mínimos de homogeneidad, una colectividad que mantenga una identidad propia, una red de relaciones comunes y el interés de continuar viviendo juntos. Conforme estas situaciones van cambiando, los mecanismos comunitarios van perdiendo eficacia, pues disminuye la posibilidad de control social sobre sus integrantes.

Mecanismos comunitarios como las rondas o las comunidades funcionan cuando existe la posibilidad del restablecimiento de las relaciones afectadas por un conflicto y la reintegración del responsable a la comunidad. No son eficaces si la gravedad de un problema, la reincidencia de uno o más involucrados, o algunas circunstancias personales hacen imposible que dicho restablecimiento se produzca.

La legitimidad de estos mecanismos se basa también en su carácter autónomo y su relación cercana con las demandas concretas de la población. Si se pretendiera extender su competencia más allá de aquello que admite la población, afectaría la propia identidad de estos mecanismos y terminaría generando un fracaso: los principales perjudicados serían los propios habitantes de las zonas rurales.

Otro problema es que no siempre comunidades y rondas solucionan todos los problemas de manera adecuada. Muchas mujeres campesinas y nativas sufren diversas formas de discriminación aun dentro de sus

28 El artículo 26 del Código Procesal Penal de Paraguay señala: «COMUNIDADES INDÍGENAS. También se extinguirá la acción penal cuando se trate de hechos punibles que afecten bienes jurídicos propios de una comunidad indígena o bienes personales de alguno de sus miembros y tanto el imputado como la víctima o, en su caso, sus familiares, acepten el modo como la comunidad ha resuelto el conflicto conforme a su propio derecho consuetudinario". En estos casos, cualquier miembro de la comunidad indígena podrá solicitar que se declare la extinción de la acción penal ante el juez de paz. Este convocará a la víctima o a sus familiares, al imputado, al representante del ministerio público y a los representantes legales de la comunidad o, cuando ellos no hayan sido nombrados, a seis miembros de la comunidad elegidos por la víctima y el imputado, a una audiencia oral dentro de los tres días de presentada la solicitud, con el fin de verificar si se reúnen los requisitos previstos en este artículo y en la constitución nacional.

29 Artículo 132. 
comunidades, lo cual genera una fuerte impunidad en casos de violencia familiar y sexual.

\section{EL PELIGROSO RELATIVISMO CULTURAL}

Existe un sector de magistrados que han interpretado el artículo 18 del CPP como un argumento para evitar intervenir en aquellos delitos que se cometen en las comunidades campesinas y nativas. Algunos pueden haber caído en una mala interpretación de la norma, pero existen también magistrados relativistas, quienes sostienen que es imposible plantear valores morales universales, incluidos los derechos humanos, que son propios de la cultura occidental y no pueden ser exigidos para las poblaciones indígenas ${ }^{30}$.

El relativismo cultural es una distorsión del respeto hacia la diversidad cultural, puesto que en nombre de dicho respeto se plantea que no existe ni siquiera el derecho a la vida o a la integridad física ${ }^{31}$. En realidad, si bien los derechos humanos han surgido en un momento propio de la historia occidental, su validez es universal y todos los seres humanos tienen derecho a ser respetados en su dignidad como tales.

Sin embargo, los magistrados relativistas consideran que tampoco deben intervenir si en la administración de justicia por parte de autoridades comunales se produce una violación a los derechos humanos, porque se trata de una expresión cultural ${ }^{12}$. La misma abstención se manifiesta frente a otros hechos cometidos por campesinos o nativos, como violencia familiar o maltrato a los niños ${ }^{33}$.

Los magistrados relativistas inclusive cuestionan la expansión de la justicia de paz porque podrían influir en las comunidades y modificar sus mecanismos tradicionales para resolver conflictos.

Esta posición ha perdido sustento a nivel internacional: en los Estados Unidos, la Asociación Americana de Antropólogos (AAA), que en

30 ARDIto VeGA, Wilfredo. «Justicia de paz en el Perú». Allpanchis, año XXXIV, № 59, Cusco, pp. 13-38 y 146.

31 Giusti explica los principales argumentos culturalistas al señalar que, para esta posición, con la concepción de derechos humanos está presente una noción individualista del ser humano, sin tomar en cuenta sus referentes culturales (p. 301). Igualmente, bajo un aparente discurso de protección de los derechos humanos, aparecen otro tipo de nociones: el derecho a la libertad individual viene acompañado del libre mercado; el derecho a la libertad de expresión se defiende en tanto se vincula con la propiedad privada de los medios de comunicación; el derecho al trabajo con un modelo económico donde prima la acumulación del capital; el derecho a la libertad de conciencia termina fragmentando la solidaridad social (pp. 299-300).

32 Durante una conversación con un magistrado que trabaja en un departamento andino este explicaba su inacción: «No se puede pretender que a los campesinos se les acuse de violar los derechos humanos. Ese es un concepto de la cultura occidental» (entrevista personal). Otros magistrados llegan a sostener que el concepto de violación no existe para la población campesina, manifestando que es una simple forma de comenzar una relación.

33 Otros magistrados llegan a sostener que el concepto de violación no existe para la población campesina. Manifiestan que es una simple forma, socialmente aceptada, de comenzar una relación (entrevistas con diversos integrantes de la Corte Superior de Ayacucho: 20 de enero de 1999, 16 de junio de 2000 y 16 de septiembre de 2000).

EL ARTÍCULO 18, INCISO 3 , DEL CÓDIGO PROCESAL PENAL: RIESGOS Y POSIBILIDADES 
décadas anteriores sostuvo públicamente la imposibilidad de llegar a un consenso sobre derechos universales, ha retrocedido en esta posición y ahora admite que existen derechos fundamentales ${ }^{34}$.

Al margen de ello, a nuestro entender detrás de este relativismo cultural subsiste una perspectiva discriminatoria: campesinos y nativos son percibidos como seres sin derechos porque sus derechos no son prioritarios para estas autoridades ${ }^{35}$. De hecho, en otras demandas de justicia por parte de campesinos, la administración de justicia se ha mostrado muy reacia a ampararlos, pese a contar con el adecuado respaldo legal (ejecuciones extrajudiciales, desapariciones, esterilización forzada, víctimas del uso indebido de la fuerza).

Estos magistrados no toman en cuenta ni la obligación de promover los derechos humanos (artículo 44 de la Constitución), ni el derecho a la tutela jurisdiccional (artículo 139 inciso 3) ni la clara referencia a los derechos humanos en el artículo 149.

En el fondo, defender como irrestricta la facultad de las comunidades para administrar justicia suele ser más un pretexto para justificar la inacción que una preocupación real por el derecho a la identidad cultural amenazada por nociones como los derechos humanos. Paradójicamente, la principal contradicción a la que llegan los relativistas es que campesinos y nativos quedan como ciudadanos de segunda categoría, que no pueden acogerse a las normas de protección de los derechos fundamentales $^{36}$.

En el fondo, el relativismo plantea una visión determinista sobre los integrantes de culturas no occidentales, al percibir a los miembros de otras culturas como seres que siguen impulsos casi biológicos o que están genéticamente determinados para obrar de cierta manera, sin admitir que puedan tener su propio discernimiento moral. Los magistrados relativistas prefieren percibir a los grupos indígenas como si fueran homogéneos, al ignorar las divergencias que pueden existir a su interior o inclusive las situaciones de opresión ${ }^{37}$.

En el relativismo existe una visión despectiva hacia otras culturas, pues sus integrantes parecen seres que no pueden comportarse sin ejercer violencia o abusar de los demás ${ }^{38}$. Lamentablemente, se generalizan

34 Desde hace tiempo, la AAA se encuentra preocupada cada vez que las diferencias entre los seres humanos se convierten en la base para la negación de los derechos humanos fundamentales, entendiendo por «humanos» en toda la amplitud de significados culturales, sociales, lingüísticos, psicológicos y biológicos (citado por Merry, 2002, p. 39, traducción nuestra).

35 ARDito VeGA, Wilfredo. «Justicia de paz en el Perú». Ob. cit., pp. 13-38 y 146.

36 lbíd., p. 147.

37 En muchas comunidades campesinas se reprime el adulterio, considerado un acto grave contra la moral. Sin embargo, muchas personas, especialmente las mujeres, contraen matrimonio a una edad muy temprana, por presión de sus familias. En estos casos donde el matrimonio no fue un acto libre, la búsqueda de una nueva relación de pareja podría ser una alternativa positiva para la realización de una persona, pero es reprimida violentamente por la sociedad.

38 BRACEY, Dorothy H. Exploring Law and Culture. Long Grove, Illinois: Waveland Press, Inc., 2006, p. 108. 
comportamientos negativos sobre todos los integrantes de estos grupos, como el desprecio por la mujer, el maltrato a los niños o el empleo desproporcionado de violencia ${ }^{39}$.

\section{UNA ALTERNATIVA DE SOLUCIÓN}

El reconocimiento del pluralismo jurídico debe buscar conciliar el respeto por la autonomía de la población campesina y nativa con el respeto por los derechos fundamentales, y plantear la posible intervención del Poder Judicial para salvaguardar estos últimos.

Respetar los mecanismos comunitarios no implica plantear un relativismo cultural según el cual inclusive puede aceptarse un crimen si está enmarcado en una práctica cultural.

Consideramos que constituye un serio error considerar las prácticas culturales como comportamientos obligatorios o aun generalizables. La obligatoriedad de las prácticas culturales depende de cada acto concreto, de cada individuo y de cada momento histórico en que una cultura está viviendo ${ }^{40}$. Individuos pertenecientes a una cultura indígena, por ejemplo, pueden optar por comportarse de manera diferente o por rehusarse a seguir aceptando prácticas que sienten que restringen sus derechos. Estas decisiones diferentes se aprecian en personas jóvenes o migrantes.

Creemos que esta tendencia se encuentra representada también en los proyectos de reforma constitucional planteados por la CERIAJUS ${ }^{41}$ y por el Acuerdo Plenario de la Corte Suprema, que menciona el respeto por los derechos humanos como una condición de legitimidad para las rondas campesinas: vale decir, estas pierden su legitimidad cuando cometen algún tipo de violación ${ }^{42}$.

El Acuerdo Plenario sanciona las violaciones a los derechos humanos dispuestas por las propias reglas consuetudinarias, pero también los abusos que pueden estar cometiendo las autoridades ronderas, las cuales, al hacerlo, vulneran su propio Derecho consuetudinario. Se trata de una distinción que es sumamente positiva y que también se debe realizar dentro del comportamiento de los agentes estatales ${ }^{43}$.

39 DECKHA, Maneesha. «The Paradox of the Cultural Defence: Gender and Cultural Othering in Canada». En Multicultural Jurisprudence. Alison Dundes Renteln y Marie-Claire Foblets (editoras). Portland, Oxford, y Portland, Oregon: 2009, p. 274.

40 La cultura occidental actúa en función de normas generales y obligatorias para todos los individuos.

41 Comisión Especial para la Reforma Integral de la Administración de Justicia (CERIAJUs). Plan Nacional de Reforma Integral de la Administración de Justicia [recurso electrónico], 2004, p. 399.

42 Acuerdo Plenario, 9.

43 Algunos casos muy sonados de violación a derechos humanos aparentemente cometidos de acuerdo al Derecho consuetudinario deberían en realidad ser reconocidos como prácticas ajenas a este (asesinato del alcalde de llave, linchamiento de abigeos, masacre de Los Naranjos, asesinato de brigadistas del Ministerio de Salud, asesinato de policías de la Estación 6). Estos hechos, sin embargo, no suelen ocurrir entre las rondas campesinas.

EL ARTÍCULO 18,

INCISO 3,

DEL CÓDIGO

PROCESAL PENAL:

RIESGOS Y

POSIBILIDADES 
Se señala que ni el derecho a la identidad étnica y cultural ni el derecho colectivo al ejercicio de la jurisdicción son absolutos y que deben ponderarse para que se respeten aquellos derechos humanos que nunca pueden derogarse, ni siquiera en un conflicto armado o un estado de excepción.

Por todo lo anterior creemos que, en materia penal, la pendiente ley de coordinación debería primero precisar que, en caso se produzca un hecho ilícito que esté fuera de la competencia de la comunidad o la ronda, las autoridades locales tienen la obligación de ponerlo en conocimiento de las instituciones estatales. En muchas oportunidades, esta labor deberá ser llevada a cabo por los jueces de paz.

Cuando se trate de ilícitos penales cuya competencia no está reservada a las instituciones estatales, las autoridades comunales o ronderas decidirán si asumen el caso o, de lo contrario, lo remitirán al juez de paz, que lo resolverá si se trata de faltas o lo remitirá a las instancias superiores si se trata de delitos.

En aquellos casos en los que la comunidad o la ronda resuelvan satisfactoriamente para los involucrados, se considerará extinguida la acción penal. Si la víctima o el imputado no están de acuerdo, podrán acudir al juzgado de paz letrado o al juzgado mixto o penal que le corresponda, de acuerdo a la gravedad del caso.

Cuando se produzca alguna sanción contraria a los derechos fundamentales, como las que señala el Acuerdo Plenario, corresponde al juez de paz poner el hecho en conocimiento del Poder Judicial, facultad de la que también gozará cualquier habitante de la comunidad.

Las autoridades estatales no intervendrán en aquellas infracciones de carácter cultural, como el adulterio o la brujería, salvo que se produzca alguna sanción contra los derechos fundamentales, pero sin resolver el problema de fondo. En su intervención, decidirán si son aplicables los artículos 14 ó 15 del Código Penal.

La Corte Suprema expresa dudas con respecto a si en el caso de los ronderos esto es posible, dado que la mayoría se encuentran «integrados al Estado total o parcialmente», por lo que «se les puede exigir algún tipo de conducta acorde a las normas del Estado ${ }^{44}$. Los casos en que existan discrepancias o dudas respecto de la competencia deberán ser resueltos por el Poder Judicial, previo informe del respectivo juez de paz.

El artículo 18 permite también que ronderos o campesinos puedan ser procesados penalmente, si pretendieran ejercer acciones que van más allá del criterio jurisdiccional, como actuar en función de intereses particulares ${ }^{45}$. Por otro lado, tratándose de un delito sobre el que solamente 
tiene competencia la jurisdicción estatal, comunidades y rondas también deberán ayudar a la investigación fiscal.

\section{CONCLUSIONES}

El reconocimiento de la administración de justicia por parte de las comunidades campesinas y nativas y de las rondas campesinas no implica considerarlas la única alternativa frente a todas las demandas de justicia de la población rural. No es admisible delegar en estos mecanismos la solución de problemas legales para los cuales no aparecieron, ni asumir que el Estado debe abstenerse de intervenir en todos los conflictos que se suscitan entre comuneros. Ni estos mecanismos están en la capacidad de enfrentar problemas como homicidio o narcotráfico ni fueron creados con esta intención.

El Poder Judicial y el Ministerio Público mantienen su obligación de proteger los intereses de los ciudadanos que habitan en las zonas rurales, especialmente sus derechos humanos. La existencia de los mecanismos comunitarios no puede interpretarse en el sentido de que el Derecho estatal, y menos aún los derechos humanos, carecen de vigencia en esos lugares.

En realidad, los mecanismos comunitarios podrían también ser utilizados desde una perspectiva que busca reducir al mínimo indispensable la intervención del Estado en la sociedad, para concentrar dicha intervención en aquellos temas que tengan mayor relevancia para los grupos de poder $^{46}$.

Una postura de aparente respeto por la diversidad cultural terminaría teniendo una carga sumamente conservadora y racista al plantearse que el Estado solo debe atender los problemas de los sectores urbanos de ascendencia occidental.

De hecho, el grave peligro con una errónea interpretación del artículo 18 del CPP es que podría generar la existencia de dos tipos de justicia: la estatal, dirigida a los sectores altos y medios, con valor oficial y con recursos estatales; y otra de segundo nivel, dirigida a los más pobres y en la que ni siquiera estarían garantizados sus derechos fundamentales o la segunda instancia.

Estos mecanismos no deben ser percibidos por la justicia penal estatal como instrumentos para reducir su carga procesal, aunque efectivamente contribuyen a ello, sino como formas para materializar el derecho de los ciudadanos a obtener justicia de manera rápida y eficaz para aquellas situaciones que el Estado no puede atender de manera efectiva.

EL ARTÍCULO 18,

INCISO 3,

DEL CÓDIGO

PROCESAL PENAL:

RIESGOS Y

POSIBILIDADES 
Por lo tanto, el reconocimiento de la función jurisdiccional a rondas y comunidades debe producirse paralelamente a una intervención activa del Estado para enfrentar las barreras que existen ante el acceso a la justicia de la población rural, de modo que sus demandas puedan ser atendidas, así como para promover cambios culturales dentro de los propios mecanismos comunitarios, en la línea de proteger los derechos de los ciudadanos más vulnerables. 